\title{
GERMINAÇÃO in vitro DE EMBRIÕES ZIGÓTICOS MADUROS DE MACAÚBA INFLUENCIADA POR TEMPERATURAS DE ARMAZENAMENTO DOS FRUTOS E CONCENTRAÇÕES DE SACAROSE ${ }^{1}$
}

\author{
Fabiana Schmidt Bandeira ${ }^{2}$, Aloisio Xavier ${ }^{3}$, Elisonete Ribeiro Garcia Lani ${ }^{4}$ e Wagner Campos Otoni ${ }^{5}$
}

\begin{abstract}
RESUMO - Este trabalho teve como objetivos avaliar a influência de temperaturas de armazenamento dos frutos e de concentrações de sacarose na germinação in vitro de embriões zigóticos maduros de macaúba (Acrocomia aculeata (Jacq.) Lodd ex Mart.). Após a colheita, os frutos foram armazenados à temperatura ambiente $\left(27 \pm 2^{\circ} \mathrm{C}\right)$ ou em câmara fria $\left(\mathrm{a} 12-15^{\circ} \mathrm{C}\right)$. Decorrido esse período, os embriões foram isolados e, imediatamente, inoculados em meio básico MS (MURASHIGE; SKOOG, 1962) suplementado com $100 \mathrm{mg} \mathrm{L}^{-1}$ de mioinositol, $2 \mathrm{~g} \mathrm{~L}^{-1}$ de carvão ativado e $6,5 \mathrm{~g} \mathrm{~L}^{-1}$ de ágar $\mathrm{Merck}^{\circledR}$. O experimento foi realizado em delineamento inteiramente casualizado, em esquema fatorial 2 x 6 . Os tratamentos consistiram da combinação de duas condições de armazenamento dos frutos após a colheita (frutos armazenados à sombra, em temperatura ambiente $\left(27 \pm 2{ }^{\circ} \mathrm{C}\right)$ ou em câmara fria a $12-15^{\circ} \mathrm{C}$, na ausência de luz, durante 30 dias, e concentrações de sacarose no meio nutritivo $(5,10$, $15,20,25$ e $\left.30 \mathrm{~g} \mathrm{~L}^{-1}\right)$. Utilizaram-se cinco repetições por tratamento, cada uma composta por cinco explantes. Consideraram-se como fonte de explantes embriões zigóticos extraídos de frutos maduros. Após 90 dias, avaliaram-se a germinação de plântulas completas, os percentuais de plântulas viáveis ou normais, plântulas que emitiram apenas primórdios de raiz e plântulas hiper-hídricas. Observou-se maior percentual de germinação nos embriões isolados de frutos mantidos em temperatura ambiente. Menor porcentagem de plântulas com primórdios de raiz foi obtida para os frutos mantidos em câmara fria. $\mathrm{O}$ meio acrescido de sacarose a $30 \mathrm{~g} \mathrm{~L}^{-1}$ contribuiu para o desenvolvimento de plântulas viáveis ou normais.
\end{abstract}

Palavras-chave: Acrocomia aculeata; Cultura de embriões; Palmeira; Propagação in vitro.

\section{In vitro GERMINATION OF MATURE ZYGOTIC EMBRYOS OF MACAW PALM INFLUENCED BY STORAGE TEMPERATURE OF THE FRUITS AND SUCROSE CONCENTRATIONS}

\begin{abstract}
The present study aimed to evaluate the influence of storage temperature on fruit and sucrose concentrations on in vitro germination of mature zygotic embryos of macaw palm (Acrocomia aculeata (Jacq.) Lodd ex Mart.). After harvest, the fruits were stored at room temperature $\left(27 \pm 2{ }^{\circ} \mathrm{C}\right)$ or cold $\left(12-15{ }^{\circ} \mathrm{C}\right)$. After this period, the embryos were isolated and immediately inoculated on MS basal medium (MURASHIGE; SKOOG, 1962), supplemented with $100 \mathrm{mg} \mathrm{L}^{-1}$ myo-inositol, $2 \mathrm{~g} \mathrm{~L}^{-1}$ activated charcoal and $6.5 \mathrm{~g} \mathrm{~L}^{-1}$ agar Merck ${ }^{\circledR}$. The experiment was conducted in an completely randomized design in a factorial $2 \times 6$. The treatments consisted of the combination of two storage conditions of the fruit after harvest (in shade, at room temperature $\left(27 \pm 2{ }^{\circ} \mathrm{C}\right)$ or at $12-15^{\circ} \mathrm{C}$ in the dark for 30 days), and sucrose concentrations in the nutrient medium (5, 10, 15, 20, 25 and $\left.30 \mathrm{~g} \mathrm{~L}^{-1}\right)$, with five replications, each consisting of five explants. Zygotic embryos extracted from mature fruits were considered as a source of explants. After 90 days, we assessed the germination of complete seedlings, the percentage of viable seedlings, seedlings with only root primordial issued, and
\end{abstract}

\footnotetext{
${ }^{1}$ Recebido em 24.09.2009 aceito para publicação em 25.06.2013.

${ }^{2}$ Departamento de Engenharia Florestal, Universidade Estadual do Centro-Oeste, UNICENTRO, Brasil. E-mail: $<$ fperes@irati.unicentro.br>.

${ }^{3}$ Departamento de Engenharia Florestal, Universidade Federal de Viçosa, UFV, Brasil. E-mail: <xavier@ufv.br>.

${ }^{4}$ Instituto de Biotecnologia Aplicada à Agropecuária (BIOAGRO), Universidade Federal de Viçosa, MG. E-mail: $<$ elisonete@yahoo.com.br>.

${ }_{5}^{5}$ Departamento de Biologia Vegetal, Universidade Federal de Viçosa, UFV, Brasil. E-mail: <wotoni@ufv.br>.
}

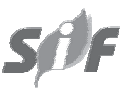

Revista Árvore, Viçosa-MG, v.37, n.4, p.691-700, 2013 
hyperhydric plantlets. There was a higher percentage of germination in embryos isolated from fruits stored at room temperature. Lower percentage of seedlings with root primordia was obtained for fruits under cold storage. The medium supplemented with sucrose at $30 \mathrm{~g} \mathrm{~L}^{-1}$ contributed to the development of viable or normal seedlings.

Keywords: Acrocomia aculeata; Embryo culture; in vitro propagation; Palm tree.

\section{INTRODUÇÃO}

A macaúba [Acrocomia aculeata (Jacq.) Lodd ex Mart.] é uma palmeira tropical, pertencente à família Arecaceae, com ampla distribuição geográfica. Ocorre na forma de extensos povoamentos naturais em praticamente todo o território brasileiro. É uma espécie que habita áreas abertas, com elevada incidência solar, bem adaptada a solos arenosos e com baixo índice hídrico (LORENZI, 2006).

A palmeira macaúba apresenta grande potencial para produção de óleo, com vasta aplicação nos setores industriais e energéticos, apresentando vantagens sobre outras oleaginosas, principalmente em relação à sua maior rentabilidade agrícola e à produção total de óleo (MOTTA et al., 2002). No entanto, a exploração dos povoamentos naturais ainda ocorre de forma extrativista, inviabilizando o desenvolvimento de empreendimentos industriais mais ousados. Esse fato aponta para a necessária substituição da atividade extrativa por cultivos racionais, possibilidade que ganha impulso com a busca de alternativas em face da crise energética atual (SILVA, 1994).

A macaúba tem sido apontada como a palmeira oleaginosa mais importante, comercialmente, no contexto brasileiro, dada a possibilidade de seus frutos fornecerem 20 a 30\% de óleo, 5\% de farinha comestível, 35\% de tortas forrageiras e $35 \%$ de combustível de alto poder calórico. Diante da necessidade atual de fontes alternativas de energia, é considerada uma das espécies nativas com alta potencialidade para o fornecimento de óleo para produção de biodiesel (SILVA, 1994; NAE, 2005).

A propagação ocorre exclusivamente por sementes, as quais, em condições naturais, podem levar de um a dois anos para germinar (LORENZI, 2006). Para Broschat (1994), a germinação de sementes de muitas espécies de palmeiras é, em geral, lenta, irregular e ocorre em baixa porcentagem, além de perderem a viabilidade rapidamente, quando desidratadas. Esse comportamento caracteriza a natureza recalcitrante das sementes dessas espécies, justificando a necessidade do desenvolvimento de métodos especiais de armazenamento que assegurem a conservação das sementes, impedindo a perda de viabilidade dos embriões. No caso de sementes de macaúba, a escassez de informações é ainda maior, o que faz que a produção de mudas da espécie seja um grande desafio (COSTA; MARCHI, 2008).

Para solucionar os problemas decorrentes das dificuldades de germinação in situ e da desuniformidade das plântulas formadas, a propagação in vitro, via cultura de embriões, constitui ferramenta de grande valia na produção de mudas dessas espécies. A propagação in vitro permite, entre outras aplicações, a produção de plantas livres de patógenos e a aceleração dos programas de melhoramento. Esses programas, com relação a palmeiras, são demorados e complexos, em virtude do longo ciclo, hábito de crescimento e ausência de métodos convencionais de propagação vegetativa, já que a produção de perfilhos está restrita a algumas espécies apenas (LEDO et al., 2001).

A cultura de embriões zigóticos é uma técnica de propagação in vitro, frequentemente empregada na propagação e conservação de muitas palmeiras. E resultados promissores, representados principalmente pelo aumento das taxas de germinação, de uniformidade das plantas e conversão de plântulas viáveis, têm sido relatados para espécies como Cocos nucifera (ASHBURNER et al., 1993; SILVA, 2002; MOLLA et al., 2004; LEDO et al., 2007; PECH-AKÉ et al., 2007), Bactris gasipaes (STEINMACHER, 2005; TZEC-SIMÁ et al., 2006), Euterpe oleracea (LEDO et al., 2001), Syagrus oleracea (MELO et al., 2001), Mauritia flexuosa (SPERA et al., 2001), Astrocaryum ulei (PEREIRA et al., 2006) e Hyophorbe lagenicaulis (SARASAN et al., 2002). Os resultados desses trabalhos, a partir da aplicação da cultura de embriões em diversas palmeiras, apontam para o potencial dessa técnica em viabilizar a produção de mudas nessas espécies em que, naturalmente, as dificuldades de germinação têm constituído entrave ao estabelecimento de plantios racionais e de alta produtividade. 
Ao contrário do observado em algumas espécies comerciais de palmeiras, por exemplo Cocos nucifera (SILVA, 2002; SANTANA et al., 2003; LEDO et al., 2007) e Phoenix dactylifera (IOSSI et al., 2003), muito pouco se conhece a respeito das condições adequadas de temperatura e de requerimento energético da macaúba no ambiente in vitro, com vistas à obtenção de plântulas vigorosas e com maiores possibilidades de sobrevivência na fase de aclimatização.

Este trabalho teve por objetivo avaliar diferentes temperaturas de armazenamento de frutos e o efeito de concentrações de sacarose na germinação in vitro de embriões zigóticos maduros de macaúba (Acrocomia aculeata).

\section{MATERIAL E MÉTODOS}

Os experimentos foram realizados no Laboratório de Cultura de Tecidos do Instituto de Biotecnologia Aplicada à Agropecuária $\mathrm{BIOAGRO}$, da Universidade Federal de Viçosa, em Viçosa, Minas Gerais.

Foram utilizados como fonte de explantes frutos maduros colhidos de plantas adultas de populações naturais no Campus da Central de Ensino e Desenvolvimento Agrário de Florestal - CEDAF, nos Municípios de Florestal e Rio Paranaíba, Minas Gerais, nos meses de janeiro a dezembro.

Previamente à extração dos embriões, os frutos tiveram seus pericarpos removidos. Após a remoção do pericarpo, os frutos foram colocados para secar na temperatura ambiente $\left(27 \pm 2^{\circ} \mathrm{C}\right)$ e em câmara fria (12 a $15^{\circ} \mathrm{C}$, na ausência de luz), por aproximadamente 30 dias, antes do isolamento dos embriões.

Os frutos foram quebrados com o auxílio de um torno manual para remoção do endocarpo e liberação da amêndoa, que contém, em seu interior, o embrião zigótico. As amêndoas foram previamente desinfestadas por imersão em solução de hipoclorito de sódio comercial a 5\%, v/v (Super Globo, Brasil), por $20 \mathrm{~min}$, seguida de três enxagues sucessivos em água desionizada e autoclavada, sendo mantidas à temperatura ambiente por $24 \mathrm{~h}$, para secagem. Posteriormente, procedeu-se à extração dos embriões.

Embriões maduros foram isolados com auxílio de bisturis e, em condições assépticas, desinfestados por imersão em solução de hipoclorito de sódio comercial a 1\%, v/v, (Super Globo, Brasil), acrescida de três gotas do surfactante Tween- $20^{\circledR}$ para cada $100 \mathrm{~mL}$ de solução, durante 15 minutos, seguida de quatro enxagues sucessivos em água desionizada e autoclavada.

Os embriões zigóticos maduros foram inoculados em meio basal MS (MURASHIGE; SKOOG, 1962), suplementado com $100 \mathrm{mg} \mathrm{L}^{-1}$ de mioinositol, $2 \mathrm{~g} \mathrm{~L}^{-1} \mathrm{de}$ carvão ativado e 6,5 $\mathrm{g} \mathrm{L}^{-1}$ de ágar Merck ${ }^{\circledR}$ como agente gelificante.

O experimento foi conduzido em delineamento inteiramente casualizado, em esquema fatorial $2 \times 6$. Os tratamentos consistiram da combinação de duas condições de armazenamento dos frutos após a colheita (frutos armazenados à sombra, em temperatura ambiente $\left(27 \pm 2{ }^{\circ} \mathrm{C}\right)$ ou em câmara fria, a 12 a $15^{\circ} \mathrm{C}$, na ausência de luz, durante 30 dias, e diferentes concentrações de sacarose no meio nutritivo $\left(5,10,15,20,25\right.$ e $\left.30 \mathrm{~g} \mathrm{~L}^{-1}\right)$. Foram utilizadas cinco repetições por tratamento, cada uma composta por cinco explantes.

Inicialmente, os embriões foram cultivados em placas de Petri estéreis de poliestireno de 60 x 15 mm (J. Prolab, Brasil). Os meios de cultura foram vertidos em câmara de fluxo laminar, em alíquotas de 12 a $15 \mathrm{~mL}$. Nessa fase, foram incorporados aos meios $300 \mathrm{mg} \mathrm{L}^{-1} \mathrm{do}$ antibiótico Timentim ${ }^{\circledR}$ (Smith-Kline Beecham, Brasil), previamente filtroesterilizado, em condições assépticas, após a autoclavagem e resfriamento dos meios nutritivos até uma temperatura de aproximadamente $50^{\circ} \mathrm{C}$.

Após 30 dias de cultivo, os embriões foram transferidos para tubos de ensaio $(150 \times 25 \mathrm{~mm})$ contendo $10 \mathrm{~mL}$ de meio de cultura fresco de mesma composição, vedados com tampas de polietileno e selados com filme de polivinilcloreto PVC (Goodyear ${ }^{\circledR}$, Brasil). O pH dos meios foi ajustado para 5,7 $\pm 0,1$, seguido de autoclavagem $\left(121^{\circ} \mathrm{C}, 1,1 \mathrm{~atm}\right.$ de pressão, $20 \mathrm{~min}$ ).

As culturas foram mantidas em estufa incubadora tipo BOD (Diurnal Growth Chamber, Forma Scientific, USA), na temperatura de $27 \pm 2{ }^{\circ} \mathrm{C}$, na ausência de luz, durante 30 dias e, a seguir, transferidas para sala de crescimento sob fotoperíodo de $16 \mathrm{~h}$, com intensidade luminosa de $36 \mu \mathrm{mol} \mathrm{m} \mathrm{m}^{-2} \mathrm{~s}^{-1}$ provida por duas lâmpadas fluorescentes (Luz do Dia Especial, $20 \mathrm{~W}$, Osram $^{\circledR}$, Brasil).

Aos 90 dias foram realizadas avaliações, em relação às variáveis: embriões germinados, percentual de plântulas viáveis ou normais, percentual de plântulas 
que não apresentaram desenvolvimento radicular ou que emitiram apenas primórdio de raiz (raiz $\leq 0,5 \mathrm{~cm}$ de comprimento) e o percentual de plântulas hiperhídricas.

Consideraram-se germinados todos os embriões que emitiram parte aérea e raiz, originando plântulas completas. O critério adotado para descrição de plântulas viáveis ou normais, além do desenvolvimento da plúmula e da raiz primária na mesma estrutura, foram a expansão foliar e, esporadicamente, o desenvolvimento de raízes secundárias. Como plântulas anormais foram consideradas aquelas com aspecto hiper-hídrico e cujo crescimento da plúmula e da raiz primária mostrou-se atrofiado, além da ausência de expansão foliar.

Os dados foram submetidos à análise de variância pelo teste $\mathrm{F}$ e as médias, comparadas pelo teste de Tukey a 5\% de significância. As análises estatísticas foram realizadas com o auxílio do software SAEG.

\section{RESULTADOS}

De maneira geral, após sete dias de inoculação em meio nutritivo, observaram-se o intumescimento dos embriões, considerado uma resposta inicial do processo germinativo; e o desenvolvimento da lâmina cotiledonar. Após 30 dias, foi possível verificar o crescimento e desenvolvimento da plúmula e da raiz primária. Aos 90 dias de cultivo, plântulas completas foram obtidas (Figura 1).

Em relação à germinação de plântulas completas de macaúba (apresentando raiz e parte aérea), não houve interação significativa entre as temperaturas de armazenamento dos frutos e as concentrações de sacarose, apenas efeito isolado desses fatores $(\mathrm{P}<0,01)$ (Tabela 1).

A germinação dos embriões zigóticos extraídos de frutos armazenados em temperatura ambiente foi significativamente superior $(84,0 \%)$, se comparada à na câmara fria $(52,6 \%)$.

No que se refere às concentrações de sacarose, acrescidas ao meio nutritivo utilizado no cultivo dos embriões, a concentração mais baixa $\left(5 \mathrm{~g} \mathrm{~L}^{-1}\right)$ resultou no pior tratamento, no qual foi observada a menor porcentagem de germinação (36\%), e diferiu significativamente das demais concentrações. Os percentuais de germinação tenderam a aumentar à medida que a concentração de sacarose foi elevada e variaram de $66 \%$, no meio contendo $10 \mathrm{~g} \mathrm{~L}^{-1}$ de sacarose, até atingir o máximo de $82 \%$ na concentração mais alta do carboidrato $\left(30 \mathrm{~g} \mathrm{~L}^{-1}\right)$. No entanto, não foi denotada diferença estatística entre as concentrações compreendidas no intervalo de 10 a $30 \mathrm{~g} \mathrm{~L}^{-1}$ de sacarose (Tabela 1).

Quanto à conversão dos embriões em plântulas viáveis ou normais aptas à aclimatização, houve efeito significativo apenas nas concentrações de sacarose utilizadas $(\mathrm{P}<0,05)$. O melhor resultado foi observado em meio contendo $30 \mathrm{~g} \mathrm{~L}^{-1}$ de sacarose, apresentando $42 \%$ das plântulas viáveis (Tabela 2). Esse tratamento diferiu estatisticamente do meio acrescido da menor concentração de sacarose $\left(5 \mathrm{~g} \mathrm{~L}^{-1}\right)$, cujo percentual de plântulas viáveis foi de apenas $2 \%$. Em relação aos demais tratamentos, não foram denotadas diferenças significativas entre as concentrações de 10 a $25 \mathrm{~g} \mathrm{~L}^{-1}$. Além disso, observou-se que concentrações reduzidas

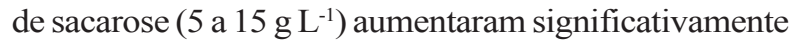
a conversão de plântulas com sintomas de hiperhidricidade ( $\mathrm{P}<0,01)$ (Tabela 2). Obtiveram-se 44, 46 e $22 \%$ de plântulas hiper-hídricas em meio com 5, 10 e $15 \mathrm{~g} \mathrm{~L}^{-1}$ de sacarose, respectivamente. Já nas maiores concentrações (20 a $30 \mathrm{~g} \mathrm{~L}^{-1}$ ) foram verificados os melhores resultados, cujos percentuais de plântulas hiper-hídricas diminuíram drasticamente para 4 e 2\% nos meios com 25 e $20 \mathrm{~g} \mathrm{~L}^{-1}$ de sacarose. Na maior concentração de sacarose $\left(30 \mathrm{~g} \mathrm{~L}^{-1}\right)$ não foram observadas plântulas hiper-hídricas.

De forma geral, nas maiores concentrações de sacarose $\left(20,25\right.$ e $\left.30 \mathrm{~g} \mathrm{~L}^{-1}\right)$ não se observaram diferenças no desenvolvimento, em que as plântulas oriundas desses tratamentos se demonstraram vigorosas e aptas à fase de aclimatização, independentemente da temperatura de armazenamento dos frutos (Figura 1D-F).

A conversão de plântulas anormais sem o desenvolvimento radicular (raiz primordial) foi influenciada significativamente pelas diferentes temperaturas de armazenamento dos frutos após a colheita e pelas concentrações de sacarose $(\mathrm{P}<0,01)$. No entanto, não houve interação significativa entre esses fatores $(\mathrm{P}>0,01)$.

O armazenamento dos frutos em câmara fria proporcionou os melhores resultados, em que foi observado o menor percentual de plântulas anormais $(14 \%)$, caracterizadas pelo desenvolvimento atrofiado 

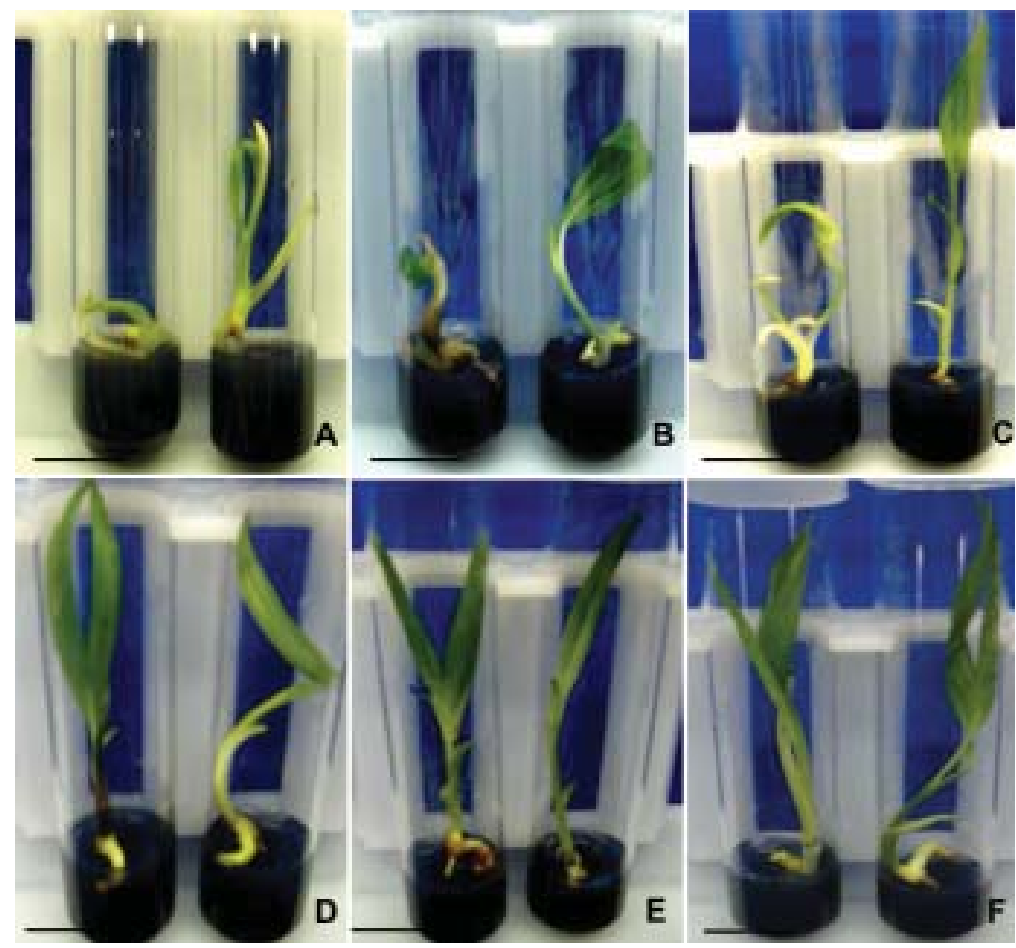

Figura 1 - Influência de temperaturas de armazenamento dos frutos (temperatura ambiente a $27 \pm 2{ }^{\circ} \mathrm{C}$ e câmara fria, a 12 a $\left.15^{\circ} \mathrm{C}\right)$ e sacarose $\left(5,10,15,20,25\right.$ e $\left.30 \mathrm{~g} \mathrm{~L}^{-1}\right)$ na germinação in vitro de embriões zigóticos maduros de macaúba (Acrocomia aculeata). Plântulas obtidas após 90 dias da inoculação. A) $5 \mathrm{~g} \mathrm{~L}^{-1}$ de sacarose; B) 10 $\mathrm{g} \mathrm{L}^{-1}$ de sacarose; C) $15 \mathrm{~g} \mathrm{~L}^{-1}$ de sacarose; D) $20 \mathrm{~g} \mathrm{~L}^{-1}$ de sacarose; E) $25 \mathrm{~g} \mathrm{~L}^{-1}$ de sacarose; F) $30 \mathrm{~g} \mathrm{~L}^{-1}$ de sacarose. Em A, B, C, D, E e F, à esquerda, plântulas obtidas de frutos armazenados à temperatura ambiente; e à direita de frutos armazenados em câmara fria, a $12-15^{\circ} \mathrm{C}$. (Barras $=20 \mathrm{~mm}$ ).

Figure 1 - Effect of the temperatures of storage of fruits (room temperature at $27 \pm 2{ }^{\circ} \mathrm{C}$ and cold chamber at $12-15{ }^{\circ} \mathrm{C}$ ) and sucrose $\left(5,10,15,20,25\right.$ and $\left.30 \mathrm{~g} \mathrm{~L}^{-1}\right)$ on in vitro germination of mature zygotic embryos of macaw palm (Acrocomia aculeata). Plantlets achieved 90 days after inoculation. A) $5 \mathrm{~g} \mathrm{~L}^{-1}$ of sucrose; B) $10 \mathrm{~g} \mathrm{~L}^{-1}$ of sucrose; C) $15 \mathrm{~g} \mathrm{~L}^{-1}$ of sucrose; D) $20 \mathrm{~g} \mathrm{~L}^{-1}$ of sucrose; E) $25 \mathrm{~g} \mathrm{~L}^{-1}$ of sucrose; F) $30 \mathrm{~g} \mathrm{~L}^{-1}$ of sucrose. A, B, C, D, E and $F$, on the left, plantlets achieved from fruits stored at room temperature; on the right, fruits stored in cold chamber, at $12-15{ }^{\circ} \mathrm{C}($ Bars $=20 \mathrm{~mm})$.

Tabela 1 - Influência de temperaturas de armazenamento dos frutos (temperatura ambiente a $27 \pm 2{ }^{\circ} \mathrm{C}$ e câmara fria, a 12 a $\left.15^{\circ} \mathrm{C}\right)$ e sacarose $\left(5,10,15,20,25\right.$ e $\left.30 \mathrm{~g} \mathrm{~L}^{-1}\right)$ na germinação de embriões zigóticos maduros de macaúba (Acrocomia aculeata), após 90 dias da inoculação in vitro.

Table 1 - Effect of the storage temperature of fruits (room temperature at $27 \pm 2{ }^{\circ} \mathrm{C}$ and cold chamber at $12-15{ }^{\circ} \mathrm{C}$ ) and sucrose $\left(5,10,15,20,25\right.$ and $\left.30 \mathrm{~g} \mathrm{~L}^{-1}\right)$ on the germination of mature zygotic embryos of macaw palm (Acrocomia aculeata), 90 days after in vitro inoculation.

\begin{tabular}{|c|c|c|c|c|c|c|c|}
\hline \multirow{3}{*}{ Armazenamento dos frutos } & \multicolumn{7}{|c|}{ Germinação in vitro dos embriões zigóticos (\%) } \\
\hline & \multicolumn{6}{|c|}{ Concentrações de sacarose $\left(\mathrm{g} \mathrm{L}^{-1}\right)$} & \multirow[b]{2}{*}{ Média } \\
\hline & 5 & 10 & 15 & 20 & 25 & 30 & \\
\hline Temperatura ambiente & 52 & 84 & 88 & 88 & 96 & 96 & 84,0 a \\
\hline Câmara fria & 20 & 48 & 60 & 60 & 60 & 68 & $52,6 \mathrm{~b}$ \\
\hline Média & $36 \mathrm{~B}$ & $66 \mathrm{~A}$ & $74 \mathrm{~A}$ & $74 \mathrm{~A}$ & $78 \mathrm{~A}$ & $82 \mathrm{~A}$ & 68,3 \\
\hline
\end{tabular}

Médias seguidas pela mesma letra maiúscula nas linhas e minúscula nas colunas não diferem significativamente pelo teste de Tukey, a $5 \%$ de probabilidade de erro.

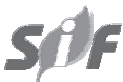

Revista Árvore, Viçosa-MG, v.37, n.4, p.691-700, 2013 
Tabela 2 - Influência da sacarose $\left(5,10,15,20,25\right.$ e $\left.30 \mathrm{~g} \mathrm{~L}^{-1}\right)$ na conversão de plântulas viáveis, plântulas com primórdio de raiz e plântulas hiper-hídricas de macaúba (Acrocomia aculeata), após 90 dias da inoculação in vitro.

Table 2 - Effect of sucrose (5, 10,15, 20, 25 and $\left.30 \mathrm{~g} \mathrm{~L}^{-1}\right)$ in the conversion of viable plantlets, plantlets with emission of only root primordial and hyperhydric plantlets of macaw palm (Acrocomia aculeata), 90 days after in vitro inoculation.

\begin{tabular}{cccc}
\hline $\begin{array}{c}\text { Concentrações } \\
\text { de sacarose }\left(\mathrm{g} \mathrm{L}^{-1}\right)\end{array}$ & $\begin{array}{c}\text { Conversão de } \\
\text { plântulas viáveis }(\%)\end{array}$ & $\begin{array}{c}\text { Plântulas hiper-hídricas } \\
(\%)\end{array}$ & $\begin{array}{c}\text { Plântulas com primórdio } \\
\text { de raiz }(\%)\end{array}$ \\
\hline 5 & $2 \mathrm{~B}$ & $44 \mathrm{~A}$ & $26 \mathrm{AB}$ \\
10 & $16 \mathrm{AB}$ & $46 \mathrm{~A}$ & $44 \mathrm{~A}$ \\
15 & $14 \mathrm{AB}$ & $22 \mathrm{AB}$ & $46 \mathrm{~A}$ \\
20 & $34 \mathrm{AB}$ & $2 \mathrm{~B}$ & $10 \mathrm{~B}$ \\
25 & $28 \mathrm{AB}$ & $4 \mathrm{~B}$ & $14 \mathrm{AB}$ \\
30 & $42 \mathrm{~A}$ & $0 \mathrm{~B}$ & $4 \mathrm{~B}$ \\
\hline
\end{tabular}

Médias seguidas pela mesma letra maiúscula nas colunas não diferem significativamente pelo teste de Tukey, a $5 \%$ de probabilidade de erro.

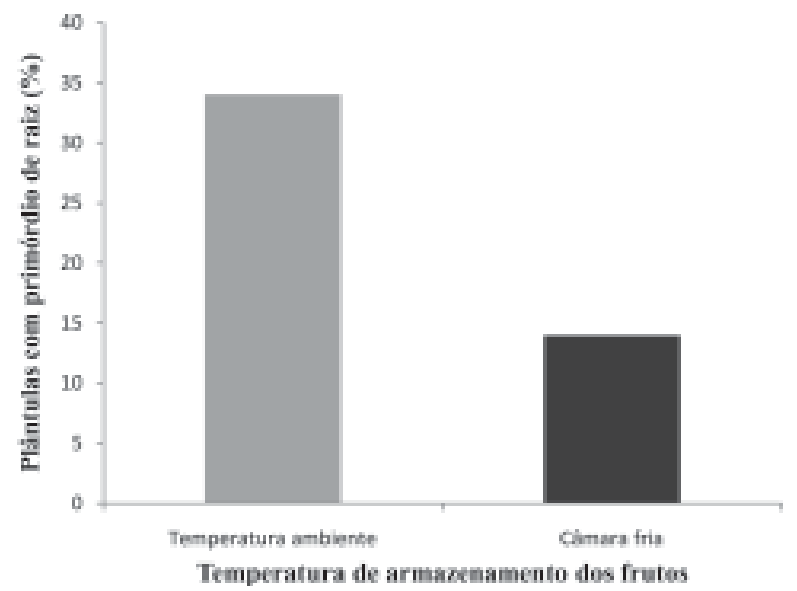

Figura 2 - Influência de temperaturas de armazenamento dos frutos (temperatura ambiente a $27 \pm 2{ }^{\circ} \mathrm{C}$ e câmara fria, a 12 a $\left.15^{\circ} \mathrm{C}\right)$ na conversão de plântulas de macaúba (Acrocomia aculeata) com primórdio de raiz (raiz $\leq 0,5 \mathrm{~cm}$ de comprimento), após 90 dias da inoculação in vitro.

Figure 2-Effect of the storage temperature of the fruits (room temperature at $27 \pm 2{ }^{\circ} \mathrm{C}$ and cold chamber at $12-15 o C$ ) in the conversion of plantlets of macaw palm (Acrocomia aculeata) with emission of only primordial root (root $\leq 0.5 \mathrm{~cm}$ of length), 90 days after in vitro inoculation.

da raiz ou apenas pela emissão de uma raiz primordial, a qual não se desenvolveu posteriormente (Figura 2). Comparativamente, em frutos mantidos à temperatura ambiente houve aumento da percentagem de conversão de plântulas incompletas (34\%), em que o sistema radicular necessita ser desenvolvido de forma a aumentar as possibilidades de sobrevivência destas plântulas ao processo de aclimatização ex vitro.
Em relação à sacarose, observou-se que os meios contendo concentrações reduzidas (10 e $\left.15 \mathrm{~g} \mathrm{~L}^{-1}\right)$ resultaram no aumento significativo dos percentuais de plântulas anormais, sem o desenvolvimento de raiz, cujos valores foram de 44 e $46 \%$, respectivamente. $\mathrm{Na}$ menor concentração $\left(5 \mathrm{~g} \mathrm{~L}^{-1}\right)$ ainda foi observado que $26 \%$ das plântulas apresentaram raiz primordial. No entanto, não foi denotada diferença estatística no cultivo das plântulas em meio com 5 e $25 \mathrm{~g} \mathrm{~L}^{-1}$ de sacarose. Os melhores resultados foram obtidos nos meios com 20 e $30 \mathrm{~g} \mathrm{~L}^{-1}$ de sacarose, os quais apresentaram os menores percentuais de plântulas com primórdio de raiz (10 e 4\%, respectivamente) (Tabela 2 ).

\section{DISCUSSÃO}

Em relação ao ambiente de armazenamento dos frutos maduros de macaúba, a condição de baixa temperatura, em câmara fria, influenciou negativamente na germinação dos embriões. Esse resultado confronta o comportamento de algumas espécies de Arecaceae em relação à manutenção da viabilidade dos embriões nas temperaturas mais baixas durante o armazenamento. Sementes de Euterpe edulis mantiveram alto poder germinativo quando conservadas por até oito meses a $15{ }^{\circ} \mathrm{C}$ (ANDRADE et al., 1996). O processo de deterioração dessas sementes foi mais acentuado na temperatura de $5{ }^{\circ} \mathrm{C}$ e atribuído aos efeitos negativos provocados pelas baixas temperaturas em sementes recalcitrantes, como a redução dos valores de germinação, frequentemente acompanhada de aumento na proporção de plântulas anormais, em geral de tamanho reduzido, e de crescimento desigual entre as partes. Martins et al. (2004) obtiveram resultados positivos 
quanto à germinação e vigor das sementes ao armazenarem frutos maduros de Euterpe edulis após a colheita por até 12 dias em temperaturas de 5,10 e $15^{\circ} \mathrm{C}$. Esses autores ressaltaram o efeito negativo mais pronunciado das baixas temperaturas, especialmente nos frutos que foram previamente despolpados por ocasião do armazenamento.

Sementes de Mauritia flexuosa toleraram o armazenamento sob baixa temperatura $\left(20^{\circ} \mathrm{C}\right)$ por um período de quatro meses e meio, mantendo-se a viabilidade e potencial morfogênico dos embriões cultivados in vitro (SPERA et al., 2001).

A porcentagem de germinação de sementes da palmeira Roystonea regia provenientes de frutos em diferentes estádios de maturação, armazenados em câmara fria, aumentou até cinco e seis meses após o armazenamento, alcançando o máximo de $98 \%$ de germinação nos frutos pretos ou imaturos e de $97 \%$ nos de cor amarela no quinto e no sexto mês de armazenamento, respectivamente (PENARIOL, 2007).

A maior sensibilidade dos frutos maduros de macaúba ao armazenamento em baixa temperatura concorda com os resultados obtidos por Penariol (2007) em estudo com a palmeira Roystonea regia, em que as sementes oriundas de frutos vermelhos em estágio de maturação mais avançado também sofreram efeitos negativos com o armazenamento em câmara fria, cuja maior porcentagem de germinação $(85 \%)$ foi obtida logo após a colheita. Observou-se ainda que as sementes provenientes de frutos maduros apresentaram maiores valores de IVG quando armazenadas por menos tempo, comparativamente aos frutos imaturos.

Negreiros e Peres (2004) relataram que, na maioria das espécies de palmeiras, a viabilidade das sementes durante o armazenamento e a tolerância à desidratação diferem entre as espécies. Os resultados deste trabalho seguem o mesmo comportamento observado em espécies como Euterpe oleraceae, Phoenix canariensis e Phoenix loureiri, palmeiras sobre as quais é relatado o comportamento tipicamente recalcitrante de suas sementes (ARAÚJO; BARBOSA, 1992; ARAÚJO et al., 1994; NASCIMENTO et al., 2010; PIMENTA et al., 2010). Em razão disso, não se recomenda seu armazenamento por longos períodos, principalmente quando os frutos já atingiram a maturidade fisiológica ou quando as sementes apresentaram teores de umidade inferiores a $40 \%$.
Segundo Villela e Peres (2004), sementes de palmeiras são, de forma geral, consideradas recalcitrantes, sendo pouco tolerantes à dessecação e muito sensíveis a baixas temperaturas, constituindo sério obstáculo para a conservação de germoplasma dessas espécies, pela dificuldade de armazenamento. Os resultados deste estudo confirmaram a maior sensibilidade dos frutos maduros de macaúba ao armazenamento em baixa temperatura, em que essa condição foi prejudicial para a germinação dos embriões cultivados. No entanto, o armazenamento dos frutos em câmara fria favoreceu a conversão de plântulas normais, as quais apresentaram o desenvolvimento da raiz.

O cultivo dos embriões de macaúba foi influenciado pelas concentrações de sacarose, em que plântulas completas puderam ser formadas em meios contendo 10 a $30 \mathrm{~g} \mathrm{~L}^{-1}$ desse carboidrato. No entanto, recomenda-se o uso da maior concentração $\left(30 \mathrm{~g} \mathrm{~L}^{-1}\right)$, visto que apresentou a maior porcentagem de plântulas viáveis $(42 \%)$, contribuindo para a maior possibilidade de sobrevivência das plantas ao processo de aclimatização ex vitro. Observou-se ainda que os meios acrescidos de concentrações mais baixas de sacarose $\left(5 \mathrm{a} 15 \mathrm{~g} \mathrm{~L}^{-1}\right)$ promoveram o desenvolvimento de plântulas com sintomas de hiper-hidricidade.

Estudos conduzidos com outras espécies de palmeiras evidenciam que a adição de maiores concentrações de sacarose ao meio de cultivo dos embriões zigóticos não influenciaram a germinação, mas têm proporcionado melhor desenvolvimento das plântulas. No cultivo in vitro de embriões zigóticos de Butia capitata foi observado que ocorreu o alongamento dos embriões na ausência de sacarose, indicando a existência neles de reservas energéticas. Entretanto, a adição de sacarose na concentração de $20 \mathrm{~g} \mathrm{~L}^{-1}$ proporcionou menores níveis de oxidação, favoreceu o alongamento e mostrou-se imprescindível para o desenvolvimento inicial de plântulas normais, apresentando bainhas foliares e raízes (RIBEIRO et al., 2011). Embriões zigóticos imaturos de Astrocaryum ulei apresentaram maior porcentagem de germinação em meio contendo $30 \mathrm{~g} \mathrm{~L}^{-1}$ de sacarose, comparativamente aos embriões maduros. Entretanto, apesar de a germinação in vitro de embriões maduros dispensar a adição de concentrações de sacarose superiores a $15 \mathrm{~g} \mathrm{~L}^{-1}$, foi verificado efeito positivo de maiores concentrações do carboidrato no crescimento posterior das plântulas (PEREIRA et al., 2006).

Revista Árvore, Viçosa-MG, v.37, n.4, p.691-700, 2013 
Ledo et al. (2007) obtiveram resultados expressivos no cultivo in vitro de embriões zigóticos de Cocos nucifera em meios contendo elevadas concentrações de sacarose (60 $\left.\mathrm{g} \mathrm{L}^{-1}\right)$, em que é descrito maior porcentagem de conversão de plântulas normais. No entanto, foi observado que o aumento da concentração de sacarose de 60 para $80 \mathrm{~g} \mathrm{~L}^{-1}$, no meio de cultura, provavelmente promoveu efeito depressivo no metabolismo das plântulas, o que resultou em maior porcentagem de plântulas anormais.

Os elevados percentuais de plântulas com primórdio de raiz observados neste trabalho, especialmente em frutos armazenados à temperatura ambiente, refletem o enraizamento insatisfatório das plântulas de macaúba in vitro, tendo como principal consequência baixos índices de sobrevivência quando transferidas para substrato durante a fase de aclimatização. Além disso, tem constituído sério obstáculo à cultura de embriões zigóticos dessa espécie. O crescimento desbalanceado entre a parte aérea e a raiz das plântulas também é apontado como um dos principais desafios ao cultivo in vitro de embriões zigóticos de Bactris gasipaes, atribuído ao efeito da formulação dos meios nutritivos utilizados (STEINMACHER, 2005). A dificuldade de enraizamento das plântulas também tem sido considerada limitação à germinação in vitro de embriões zigóticos de palmeiras como Cocos nucifera (SANTANA; TEIXEIRA, 2004; LEDO et al., 2007) e Syagrus oleraceae (MELO et al., 2001).

\section{CONCLUSÕES}

O cultivo de embriões maduros de macaúba, oriundos de frutos mantidos na temperatura ambiente, proporcionou maior porcentagem de germinação dos embriões zigóticos. A condição de armazenamento dos frutos em câmara fria favoreceu a conversão de plântulas viáveis. O meio nutritivo acrescido de $30 \mathrm{~g} \mathrm{~L}^{-1}$ de sacarose foi benéfico para a germinação dos embriões e a conversão de plântulas viáveis ou normais, passíveis de serem aclimatizadas.

\section{AGRADECIMENTOS}

À Central de Ensino e Desenvolvimento Agrário de Florestal (CEDAF), Florestal, MG, pelo fornecimento dos frutos utilizados neste estudo; e à Fundação de Amparo à Pesquisa do Estado de Minas Gerais (FAPEMIG), pela concessão da bolsa de estudos à F.S.B. e pelo apoio financeiro.

\section{REFEFÊNCIAS}

ANDRADE, A. C. S.; MALAVASI, M. M.; COSTA, F. A. Conservação de palmiteiro (Euterpe edulis Mart.): efeito da temperatura de armazenamento e do grau de umidade das sementes. Revista Brasileira de Sementes, v.18, n.2, p.149-155, 1996.

ARAÚJO, E. F.; SILVA, R. F.; ARAÚJO, R. F. Avaliação da qualidade de sementes de açaí armazenadas em diferentes embalagens e ambientes. Revista Brasileira de Sementes, v.16, n.1, p.76-79, 1994.

ARAÚJO, E. F.; BARBOSA, J. G. Influência da embalagem e do ambiente de armazenamento na conservação de sementes de palmeira (Phoenix loureiri Kunth). Revista Brasileira de Sementes, v.14, n.1, p.61-64, 1992.

ASHBURNER, G. R.; THOMPSON, W. K.; BURCH, J. M. Effect of á-naphthaleneacetic acid and sucrose levels on the development of cultured embryos of coconut. Plant Cell, Tissue and Organ Culture, v.35, n.1, p.157-163, 1993.

BROSCHAT, T. K. Palm seed propagation. Acta Horticulturae, v.1, n.360, p.141-147, 1994.

COSTA, C. J.; MARCHI, E. C. S. Germinação de sementes de palmeiras com potencial para produção de agroenergia. Informativo Abrates, v.18, n.1, p.39-50, 2008.

IOSSI, E. et al. Efeitos de substratos e temperaturas na germinação de sementes de tamareira-anã (Phoenix roebelenii O'Brien). Revista Brasileira de Sementes, v.25, n.2, p.63-69, 2003.

LEDO, A. S. et al. Cultivo in vitro de embriões zigóticos e aclimatação de plântulas de coqueiroanão. Pesquisa Agropecuária Brasileira, v.42, n.2, p.147-154, 2007.

LEDO, A. S. et al. Cultura in vitro de embriões zigóticos de açaizeiro. Revista Brasileira de Fruticultura, v.23, n.3, p.468-472, 2001.

LORENZI, G. M. A. C. Acrocomia aculeata (Jacq.) Lodd ex Mart - Arecaceae: bases para o extrativismo sustentável. 2006. 156p. Tese (Doutorado em Produção Vegetal) - Universidade Federal do Paraná, Curitiba, 2006. 
MARTINS, C. C. et al. Temporary storage of jussara palm seeds: effects of time, temperature and pulp on germination and vigor.

Horticultura Brasileira, v.22, n.2, p.271276, 2004.

MELO, B. et al. Diferentes antioxidantes no controle da oxidação, germinação e desenvolvimento das plântulas na cultura in vitro de embriões da guarirobeira (Syagrus oleracea (Mart.) Becc). Ciência e Agrotecnologia, v.25, n.6, p.1301-1306, 2001.

MOLLA, M. M. H. et al. In vitro coconut (Cocos nucifera L.) embryo culture in Bangladesh.

Biotechnology, v.3, n.1, p.98-101, 2004.

MOTTA, P. E. F. et al. Ocorrência da macaúba em Minas Gerais: relação com atributos climáticos, pedológicos e vegetacionais. Pesquisa Agropecuária Brasileira, v.37, n.7, p.10231031, 2002.

MURASHIGE, T.; SKOOG, F. A revised medium for rapid growth and biossays with tobacco tissue cultures. Physiologia Plantarum, v.15, n.3, p.473-497, 1962.

NÚCLEO DE ASSUNTOS ESTRATÉGICOS - NAE. PRESIDÊNCIA DA REPÚBLICA. Cadernos NAE: Biocombustíveis. Brasília: Núcleo de Assuntos Estratégicos da Presidência da República, 2005. 232p.

NASCIMENTO, W. M. O.; CICERO, S. M.; NOVEMBRE, A. D. L. C. Conservação de sementes de açaí (Euterpe oleracea Mart.).

Revista Brasileira de Sementes, v.32, n.1, p.24-33, 2010.

NEGREIROS, G. F.; PEREZ, S. C. J. G. A. Resposta fisiológica de sementes de palmeiras ao envelhecimento acelerado. Pesquisa

Agropecuária Brasileira, v.39, n.4, p.391396, 2004.

PECH-AKÉ, A. et al. The effect of gibberellic acid on the in vitro germination of coconut zygotic embryos and their conversion into plantlets. In Vitro Cellular and Developmental Biology-Plant, v.43, n.3, p.247-253, 2007.
PENARIOL, A. P. Germinação e morfologia de sementes de Roystonea regia (Kunth) O. F. Cook. (Arecaceae). 2007. 40f. Dissertação (Mestrado em Agronomia) - Universidade Estadual de São Paulo, Jaboticabal, 2007.

PEREIRA, J. E. S. et al. Germinação in vitro de embriões zigóticos de murmuru (Astrocaryum ulei). Ciência e Agrotecnologia, v.30, n.2, p.251-256, 2006.

PIMENTA, R. S. et al. Efeito da maturação e temperatura na germinação de sementes de Phoenix canariensis hort. ex Chabaud Arecaceae. Revista Árvore, v.34, n.1, p.31-38, 2010.

RIBEIRO, L. M. et al. Germinação de embriões zigóticos e desenvolvimento in vitro de coquinho-azedo. Revista Ceres, v.58, n.2, p.133-139, 2011.

SANTANA, M. C.; TEIXEIRA, S. L.; GOMES, J. E. Efeito da temperatura sobre a germinação in vitro de embriões zigóticos de Cocos nucifera L.

(Arecaceae). Biologia Geral e

Experimental, v.3, n.2, p.41-46, 2003.

SANTANA, M. C.; TEIXEIRA, S. L. Influência do ácido naftalenoacético no crescimento e enraizamento in vitro de plântulas de coqueiro (Cocos nucifera L.). Biologia Geral e Experimental, v.5, n.1, p.30-33, 2004.

SARASAN, V.; RAMSAY, M. M.; ROBERTS, A. $\mathrm{V}$. In vitro germination and induction of direct somatic embryogenesis in "Bottle Palm" (Hyophorbe lagenicaulis L. Bailey H. E. Moore), a critically endangered mauritian palm. Plant Cell Reports, v.20, p.1107-1111, 2002.

SILVA, J. C. Macaúba: fonte de matéria-prima para os setores alimentício, energético e industrial. Viçosa, MG: CEDAF/DEF/UFV, 1994. 41p.

SILVA, V. S. Regeneração in vitro de embriões de Cocos nucifera L. 2002. 87f. Dissertação (Mestrado em Fisiologia e Bioquímica de Plantas) - Escola Superior de Agricultura Luiz de Queiroz, Piracicaba, 2002.

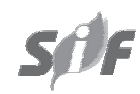

Revista Árvore, Viçosa-MG, v.37, n.4, p.691-700, 2013 
SPERA, M. R. N.; CUNHA, R.; TEIXEIRA, J. B. Quebra de dormência, viabilidade e conservação de sementes de buriti (Mauritia flexuosa).

Pesquisa Agropecuária Brasileira, v.36, n.12, p.1567-1572, 2001.

STEINMACHER, D. A. Germinação in vitro, criopreservação e embriogênese somática em pupunha. 2005. $125 \mathrm{f}$. Dissertação (Mestrado em Recursos Genéticos Vegetais) - Universidade Federal de Santa Catarina, Florianópolis, 2005.
TZEC-SIMÁ, M. A.; ORELLANA, R.; ROBERT, M. L. In vitro rescue of isolated embryos of Bactris major Jacq. and Desmoncus orthacanthos Mart., potentially useful native palms from the Yucatan peninsula (Mexico). In Vitro Cellular and Developmental Biology-Plant, v.42, n.1, p.54-58, 2006.

VILLELA, F. A.; PERES, W. B. Coleta, beneficiamento e armazenamento. In: FERREIRA, A. G.; BORGHETTI, F. (Org.). Germinação: do básico ao aplicado. Porto Alegre: Artmed, 2004. p.265-281. 